\title{
НОВЫЕ МУТАЦИИ В ГЕНЕ ДИСТРОФИНА У БОЛЬНЫХ МЬШЕЧНОЙ ДИСТРОФИЕЙ ДЮШЕННА
}

\section{NEW MUTATIONS \\ IN THE DYSTROPHIN GENE IN PATIENTS WITH MUSCULAR DUSHENN DYSTROPHY}

\author{
S. Aghayeva \\ A. Mamedov \\ A. Mamedbeyli \\ L. Valiyeva
}

Summary. Mutations in the dystrophin gene are the cause of Duchenne muscular dystrophy (DMD), a severe neuromuscular disease that causes death in male patients in 20 years. For the first time, a molecular methods used for analysing the structure of this gene in member of two ethnically different families from Azerbaijan with a diagnosis of DMD. Two distinct mutations were identified (a deletion of a large region spanning 13 exons ((8 to 20) and a deletion of exon 45) associated with two different ethnic groups of the population of Azerbaijan.

The research work was carried out in the laboratory of human genetics of the Institute of Genetic Resources of Azerbaijan National Academy of Sciences and the laboratory of Molecular Biology and Genetics of Western Caspian University.

Keywords: Duchenne muscular dystrophy, creatine phosphokinase, dystrophin gene, exon, mutation.

\section{Введение}

$\mathbf{H}$ аследственная болезнь мышечная дистрофия Дюшенна впервые была описана в 1830 году английским анатомом-хирургом Чарльзом Белла. Частота болезни приблизительно 1: 3500-4000 новорожденных мальчиков[6]. Это расстройство обычно
Агаева Салтанат Ариад

Д.ф.п.б., в.н.с., Институт Генетических Ресурсов Национальной Академии Наук Азербайджана; старший преподаватель, Азербайджанский Государственный Педагогический Университет, Баку, Азербайджан saltanat.genetic@gmail.com

Мамедов Аяз Мамед

Д.ф.п.б., н.с., Институт Генетических Ресурсов Начиональной Академии Наук Азербайджана; заведующий лабораторией, Западно-Каспийский Университет, Баку, Азербайджан ayaz_mamadov@yahoo.com

Мамедбейли Айтен Камал

Д.м.н., профессор, Азербайджанский Медицинский Университет, Баку, Азербайджан ayten2001@mail.ru

Валиева Лейла Садраддин

Д.ф.п.б., в.н.с., Институт Генетических Ресурсов Национальной Академии Наук Азербайджана, Баку,

Азербайджан

I.valiyeva@yandex.ru

Аннотация. Мутации в гене дистрофина (DMD) являются причиной мышечной дистрофии Дюшенна (мдД) - тяжелого нейромышечного заболевания, приводящего к 20 годам к смерти пациентов мужского пола. Впервые, методом молекулярной диагностики MLPA (multiplex legationdependent probe amplification) разработанным лабораторией был проведен анализ структуры этого гена у членов двух этнически различающихся семей из Азербайджана с диагнозом мдД. Были идентифицированы две различающиеся мутации (делеция большого региона, охватывающего 13 экзонов (от 8-го до 20-го) и делеция 45-го экзона), соотнесенные с двумя различными этническими группами населения Азербайджана.

Исследовательская работа проводилась в лаборатории генетики человека Института Генетических Ресурсов Национальной Академии Наук Азербайджана и лаборатории Молекулярной Биологии и Генетики Университета Западного Каспия.

Ключевые слова: мышечная дистрофия Дюшенна, креатинфосфокиназа, ген дистрофина, экзон, мутация.

проявляется в возрасте 2-3 лет. Слабость затрагивает проксимальные мышцы, как правило, начиная от нижних конечностей. Дети часто ходят на пальцах, имеют походку вразвалку и лордоз. Таким детям сложно бегать, прыгать, подниматься по ступенькам и вставать с пола. Они часто падают и получают переломы рук или ног (примерно у 20\% больных). Наблюдается стабиль- 
ное прогрессирование слабости, и почти у всех детей развиваются сгибательные контрактуры конечностей и сколиоз. Последствия вовлечения сердечной мышцы включают в себя дилатационную кардиомиопатию, нарушения проводимости и аритмии. Большинство детей пользуются инвалидной коляской в возрасте до 12 лет и умирают от респираторных осложнений к 20 годам.

На поражение мышц и последующие дистрофические процессы указывает повышение фермента креатинфосфокиназы (КФК) в крови. КФК - это фермент, катализирующий превращение креатина в креатинфосфат, обеспечивая этим энергию мышечных сокращений. В больших количествах $\mathrm{MM}$ - изомерная фракция КФК (от английского «muscle» - мышца) поступает в кровоток при повреждении мышечных клеток, что является одним из важных диагностических критериев мышечной дистрофии[10].

Причиной этой патология являются мутации в гене, кодирующем белок дистрофин, вследствие которых он вырабатывается в недостаточном количестве или вовсе отсутствует. Поскольку дистрофин является основой мышечных волокон, у детей с дистрофией Дюшенна мышцы постепенно ослабевают, перерождаются и заменяются жировой или соединительной тканью, что постепенно приводит к инвалидизации.

Ген дистрофина расположен в X половой хромосоме (локус Хр21.2) и наследуется по рецессивному типу $[1,2,7,8,9]$. Состоящий из 79 экзонов и 78 интронов, ген дистрофина является одним из наибольших генов человека длиной 2,6 миллиона нуклеотидных оснований - (DMD.OMiM:300377). Приблизительно 60\% всех мутаций в гене дистрофина приходится на долю малых и больших делеций экзонов, а $30 \%$ - это точковые мутации. 10\% мутаций встречается в виде дупликаций и транслокаций. 98\% всех мутаций приходится на долю первых 27 экзонов, область которых названа «кипящей» частью гена. В районе 48, 49, 50 и 51 экзонов, так называемой «горячей» части гена, также регистрируется высокая мутационная активность. Целью наших исследований было молекулярно-генетическое изучение гена дистрофина в двух семьях из различных этнических групп Азербайджана.

\section{Материалы и методы}

Материалом для анализа служила кровь пациентов, забранная во время экспедиций в два региона Азербайджанской Республики: Астаринский и Белоканский. Эти регионы расположены на удалении 400 км друг от друга. Астаринский район расположен на берегу Каспийского моря на юго-востоке страны, население которого - этнические талыши. Белоканский район расположен на северо-западе Республики в предгорье Большого Кавказа, большая часть его населения относится к аварской этнической группе. В каждом из этих регионов выявлено по одной семье с наследственной болезнью мдД.

Определение активности креатининфософокиназы в венознозной крови пациентов проводили в соответствии с методикой[1].

Ген миопатии Дюшенна анализировали с помощью метода секвенирования нового поколения (NGS), основанного на анализе ампликонов. Полученные ампликоны полностью охватили кодирующий регион гена вместе с высоко консервативными областями экзон-интронных сшивок. Минимальное покрытие для каждого ампликона было >20x. Для достижения 100\%-го охвата, регионы гена с отсутствущими данными и/или данными низкого качества были дополнены классическим секвенированием по Сенгеру. Варианты релевантности, определенные NGS, непрерывно и в индивидуальном порядке оценивались на месте по критериям качества: те варианты, которые отвечали внутренним стандартам качества (основываясь на процессах экстенсивной оценки) секвенированию по (енгеру не подлежали. Стандартная запись последовательности в международной базе: DMD: NM_004006.2.

Исследовательская работа проводилась в лаборатории генетики человека Института Генетических Ресурсов Национальной Академии Наук Азербайджана и лаборатории Молекулярной Биологии и Генетики Университета Западного Каспия.

При тестировании делеций и/или дупликаций гена миопатии Дюшенна были проведены анализы MLPA (multiplex legation-dependent probe amplification). ДНК выделяли из лейкоцитов с использованием стандартных протоколов высаливания, а качество и количество ДНК проверяли с помощью нанокапельного спектрофотометра.

MLPA-анализ проводили согласно инструкциям производителя (MRC Holland, Амстердам, Нидерланды). 200-500нг ДНК денатурировали и гибридизовали в течение ночи при $60^{\circ} \mathrm{C}$ со смесью зондов SALSA P034 (экзоны DMD1-10, 21-30, 41-50 и 61-70). Затем образцы обрабатывали ДНК-лигазой в течение 15 мин при $54{ }^{\circ} \mathrm{C}$. Реакцию останавливали инкубацией при $98{ }^{\circ} \mathrm{C}$ В течение 5мин. Наконец, амплификацию ПЦР проводили со специфическими флуоресцентно меченными праймерами ПЦР. Продукты амплификации подвергали электрофорезу на генетическом анализаторе ABI PRISM 3100. Полученные данные были проанализированы с помощью электронных таблиц Р034, предоставлен- 
Таблица 1. Активность креатининфосфокиназы в сыворотке крови членов семьи А.

\begin{tabular}{|l|l|l|l|l|}
\hline \multirow{2}{*}{ № } & Пациенты & Результат & Норма, Ед/л & Норма для мужчин \\
\cline { 4 - 6 } & Аорма для женщин & $38-137$ \\
\hline 2 & А.Э & 12102.6 & $26-140$ & $38-137$ \\
\hline 3 & А. Б & 9966.7 & $26-140$ & $38-137$ \\
\hline 4 & Мать & 14505.8 & $26-140$ & $38-137$ \\
\hline
\end{tabular}

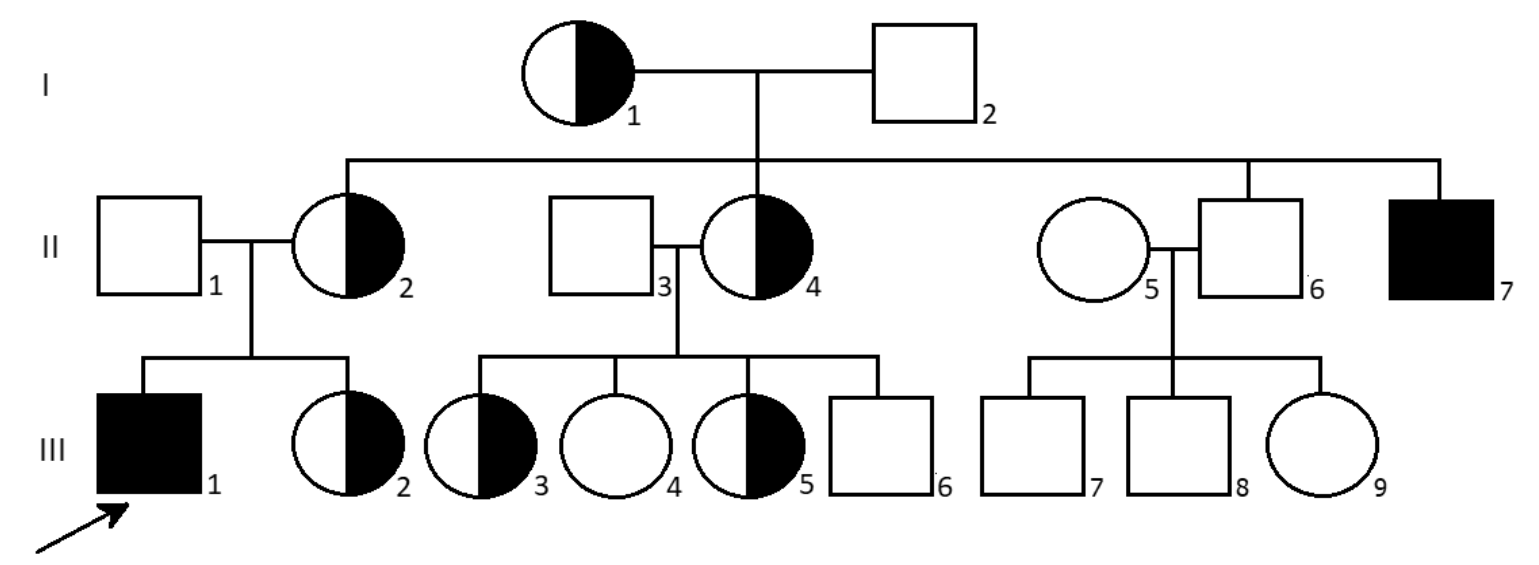

Рис. 1. Родословная семьи пробанда Н.А. с мышечной дистрофией Дюшенна. III-1- пробанд, II-1отец пробанда, II-2 - мать пробанда, III-2 — сестра пробанда, II-4- тетя пробанда, II-6 и II-7 — дяди пробанда со стороны матери, III-3, III-4, III-5, III-6, III-7, III-8 и III-9 - двоюродные сибсы пробанда, I-1дедушка пробанда и I-2 - бабушка пробанда.

ных Национальной генетической справочной лабораторией Манчестера.

\section{Результаты}

Для всех членов обеих семей с пациентами с подозрением на мышечную дистрофию Дюшенна был проведен биохимический анализ активности фермента креатининфосфокиназы (КФК) в сыворотке крови [4,5] в качестве диагностического критерия мдД.

В Астаринском районе на основании клинического проявления у трех братьев из семьи А (этнических талышей) было подозрение на мышечную дистрофию Дюшенна. Результаты анализа активности фермента КФК в сыворотке крови трех братьев и их матери представлены в таблице[3].

Как видно в таблице 1, по сравнению с нормальными показателями у всех трех братьев была выявлена высокая, во много раз превосходящая эти же показатели у здоровых людей, активность фермента КФК: от 9966,7 ед/л до 14505,8 ед/л. Уровень КФК у матери также был повышен - 786,5 ед/л.

В Белоканском районе был выявлен мальчик Н.А. с характерными клиническими проявлениями болезни мышечная дистрофия Дюшенна. Была составлена родословная его семьи, отображающая у её членов присутствие, отсутствие или носительство болезни мдД в сочетании с выявленными показателями активности КФК (рисунок 1).

У пробанда (III-1) и у дяди пробанда (II-7) уровни активностей ферментов КФК были увеличены, в обоих случаях они были выше 2000,0 ед/л. Уровень активности КФК у гетерозигот-женщин варьировал в пределах 22.2-1271,0 ед/л, при среднем показателе - 1005 ед/л.

Как видно из родословной, дядя пробанда (II-7) имел болезнь Дюшенна, а мать (II-2) и тетя пробанда (II-2) являются носителями патологического гена Дюшенна. Родная сестра пробанда (III-2), его бабушка (I-1), тетя (II-4) и двоюродные сестры (III-3 и III-5) также являются 
Resultfile: MLPA_2778h_F02_1_(62599326_P034-B2 P034-B2

Control:

Control:

Control:
MLPA_2778h_E04_1_62248360_P034-B2 P034-B2 MLPA_2778h_D04_1_(62234164 P034-B2 P034-B2 MLPA_2778h_C04_1_(62224508_P034B2̌ P034-B2
06/20/2019 08:24:49

$06 / 20 / 201908: 24: 49$

06/20/2019 08:24:49

$06 / 20 / 2019$ 08:24:49 total peak area: 1000200

compl. TV SFO [06/20/2019 08:28:08] compl. TV SFO [06/20/2019 08:27:02] compl. TV SFO [06/20/2019 08:26:38]

\section{data correction: on \\ DNA dosage: ok \\ total peak area: $\quad$ ok \\ max peak area: ok \\ max peak height: ok}

\section{Analysis Mode: Gene vs ctrl}

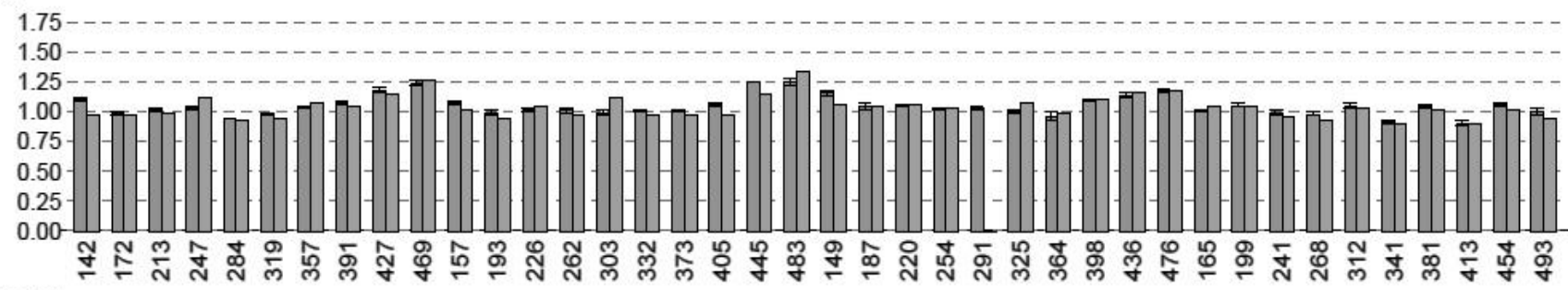

$200 \%$

$150 \%-$

$100 \% \bar{\square}$ \%

$50 \%$

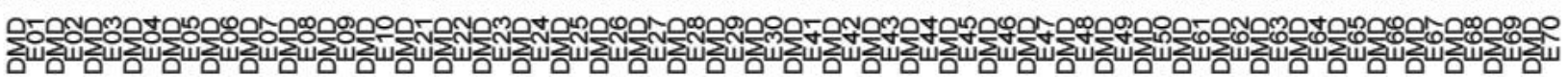

Рис. 2. Результат MLPA анализа у больного A.P.

\section{Analysis Mode: Gene vs ctrl}

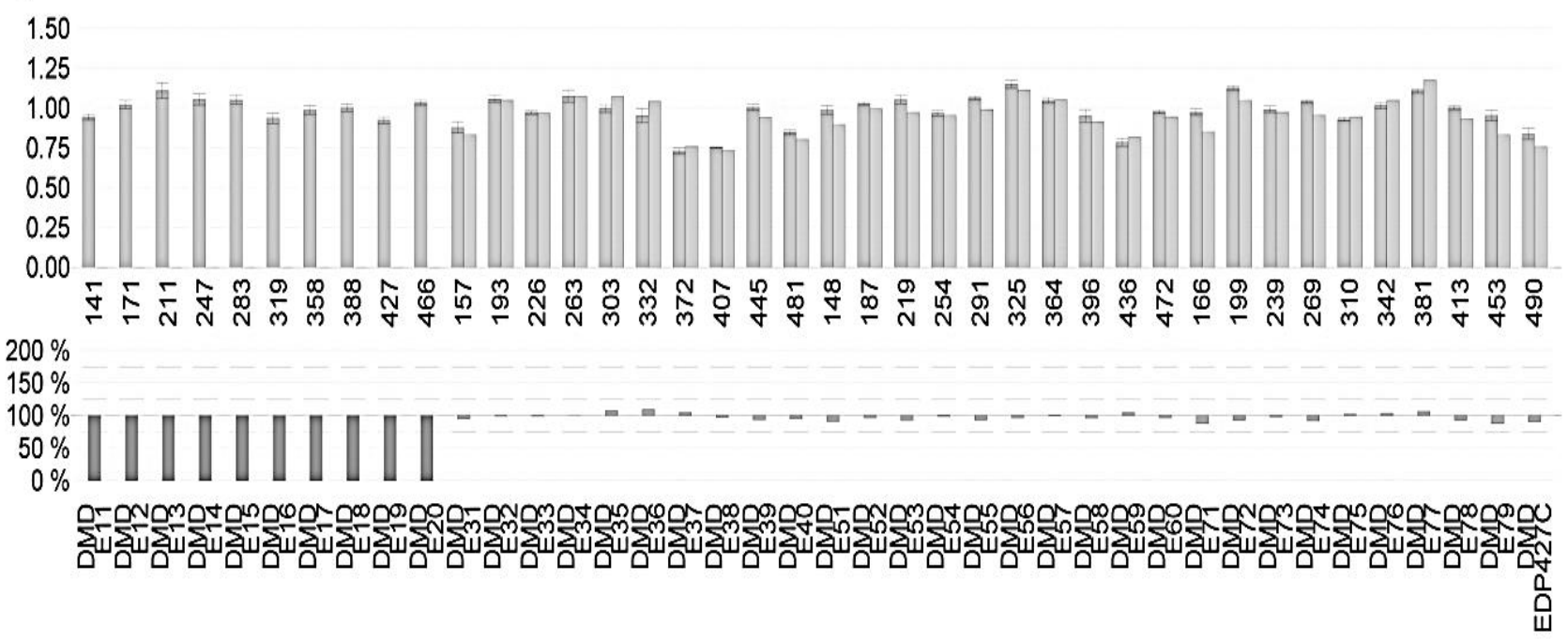

Рис. 3. Результаты генетического анализа пробанда Н.А. 
гетерозиготными носителями гена болезни Дюшенна. Следовательно, из 16-ти членов семьи Н.А. пять женщин и двое мужчин имеют патологический ген болезни мышечной дистрофии Дюшенна [5].

Результаты молекулярно-генетического анализа гена дистрофина представлены на рисунке 2.

У всех трех братьев с диагнозом мышечная дистрофия Дюшенна выявлена делеция 45-го экзона из 79 существующих в гене дистрофина.

Результаты генетического анализа пробанда Н.А. представлены на рисунке 3.

У пробанда Н.А. в отличие от предыдущего больного А.Р. была выявлена делеция протяженностью в 13 экзонов из 78 существующих в гене дистрофина, охватывающая регион с 8-го экзона по 20-й экзон.
Таким образом, была изучена молекулярная структура гена дистрофина пациентов из различных регионов Азербайджана с диагнозом мышечной дистрофии Дюшенна. В южном - Астаринском районе у пациента A.P.- этнического талыша была выявлена делеция 45-го экзона в гене дистрофина. В отличие от него, у больного Н.А.- этнического аварца из северного Белоканского района была обнаружена делеция в гене дистрофина длиной в 13 экзонов, с 8-го по 20-й экзон. В результате выполненного исследования были идентифицированы две различающиеся мутации гена дистрофина - делеция 13-ти экзонов (с 8-го до 20-го) и делеция 45-го экзона, которые были соотнесены с двумя различными этническими группами населения Азербайджана.

Учитывая репродуктивный возраст родителей, во время последующей беременности им была настоятельно рекомендована пренатальная диагностика плода.

1. Бочков Н.П. (2002). Медицинская генетика. М.: Москва, 298 с.

2. Чухрова А.И. (1997). Анализ мутаций в гене дистрофина. Автореф.канд.дисс. М., Институт медицинской генетики, АМН. 25 с.

3. Aghayeva S.A., Mamedbeyli A.K., Rasulov E.M. (2018). Creatinkinase activities polymorphism study in three families with duchenne muscular dystrophy from Azerbaijan republic. Journal of Pediatry. Kazakhistan ISSN1811-8666 N4(94), p.73-77

4. Aghayeva S.A., Huseynova L.S., Valiyeva G.A., Yusufova Kh., Badalova N.A. (2018) Genetic research of Duchenne muscular dystrophy and galactosemia from Azerbaijan Republic. International conference of European Academy of Science, November 20-28, Bonn, Germany. (ISBN9781792197710) p.88

5. Huseynova L.S., Aghayeva S.A., Mammadova S.N., Mahmudova P.A. (2018). Molecular genetic studies of the diseases Duchenne muscular dystrophy, Phenylketonuria and Familial Mediterranean fever in the population of the Azerbaijan Republic. Sylwan.,163(5), (Thomson Reuters) ISSN0039-7660.

6. McKusick A. (2002). Mendelian inheritance in man. Tenth edition, London, p. 2115.

7. Torella D., Ellison G.M., Karakikes I., Nadal-Ginard B. (2007). Growth-factor-mediated cardiac stem cell activation in myocardial regeneration. Nature Clinical1 Practice Cardiovascular Medicine. V.4: p.46-S51.

8. Ueda T., Yoshida M. (2001). Hematopoetic capability of CD34+ cord blood cells: a comparison with CD34+ adult bone marrow cells//Int J Hematol, 73(4): 45762.

9. Wang J.S., Shum-Tim D. (2001). The coronary delivery of marrow stromal cells for myocardial regeneration: pathophysiologic and therapeutic indications.//J Thorac Cardiovasc Surg. 122(4):699-705.

10. Rahul Tyagi, Sumit Kumar, Ashwin Dalal, Faruq Mohammed, Manju Mohanty, Paramvir Kaur, Akshay Anand. Repurposing Pathogenic Variants of DMD Gene and its Isoforms for DMD Exon Skipping Intervention. Journal Current Genomics, V 20, D0I:10.2174/1389202920666191107142754.

( А Агаева Салтанат Аршад ( saltanat.genetic@gmail.com ), Мамедов Аяз Мамед ( ауаz_mamadov@yahoo.com ),

Мамедбейли Айтен Камал ( ayten2001@mail.ru ), Валиева Лейла Садраддин ( I.valiyeva@yandex.ru ).

Журнал «Современная наука: актуальные проблемы теории и практики» 